\title{
Creativity Oriented Originality in Non-Protection of Ideas: Inter- Compliance of Originality and Idea-Expression Dichotomy
} Ismanjanov $A^{*}$

PhD in Law, LLM, University of Westminster, 309 Regent St, Marylebone, London W1B 2HW, UK

*Corresponding author: Akbar Ismanjanov, PhD in Law, LLM, University of Westminster, 309 Regent St, Marylebone, London W1B 2HW, UK, Tel: +44 20 7911 5000; E-mail: ismanjanov@gmail.com

Rec date: Apr 04, 2017, Acc date: May 05, 2017, Pub date: Aug 20, 2017

Copyright: (c) 2017 Ismanjanov A. This is an open-access article distributed under the terms of the Creative Commons Attribution License, which permits unrestricted use, distribution, and reproduction in any medium, provided the original author and source are credited.

\begin{abstract}
Originality and Idea-Expression Dichotomy as key concepts of copyrights that define protectable domain can be considered as mutually contradictory phenomena. Non-protection on ideas in Idea-Expression dichotomy is incongruent with the creativity orientation of originality, since the attainment of necessary level of creativity necessitates more of less idea-wise operation. Contradiction has mitigated by lower threshold of originality in line with overall non-monopolistic effect of the copyrights. Different dimensions of operation of these standards may be mitigating the conflict of these concepts, as idea-expression dichotomy focusing on non-monopolization of ideas, while in originality the attention to the minimum level of creativity. The added complexity of the problem reminds on unsuitability of the legal instrument in distinguishing the creativity as a process. While essential goal of originality is in distinguishing the creativity rather than labor or expression, and the product of creativity can be seen as more idea-wise, even if being an expression, as ideas are also expressed in the same form. The obvious contradiction is that ideas being results of creativity are excluded from the protection by idea-expression dichotomy. Some constructive but subtle primacy of originality over the idea-expression dichotomy is still perceptible, that can potentially mitigate the conflict of these concepts.
\end{abstract}

Keywords Creativity; Non-protection; Dichotomy; Copyright; Civil law; Common law jurisdictions; Infringements

\section{Introduction}

The Originality and the Idea-Expression dichotomy are the two major concepts of copyright that define the protectable domain of copyrighted works. While originality focuses on the protection of works having minimum level of creativity, the idea-expression dichotomy focuses on the protection of the works that are distinctively expressed. Utilitarian value of the standards is that originality excludes the fact-based works lacking of creativity, while the idea-expression dichotomy excludes protection of ideas.

In the direct interrelation of the creativity and ideas, raising the question whether non-protection of ideas of idea-expressions dichotomy may be contradicting with the creativity requirement of the originality, as creativity seems to be more or less idea-wise concept, rather than expression or fact oriented. It is crucial to examine whether considered concepts are inter-complementary rather than contradictory? Perhaps from the legal viewpoint it may be possible to establish the primacy of the one concept over another, hence eliminating the conflict of doctrines and smooth operation of standards.

\section{Review of Literature}

The subsistence of copyrights is contributing to its lax regime, giving longer protection in exchange of lower monopolistic effect. However the added complexity of the problem is in copyright protection being effective without formalities [1], that does not allow inferring protect ability of the object with absolute certainty, until the matter reaches the courtroom or at least goes through the examination in the copyright office. Unforseeability of the consequence of actions of the authors may be prejudicing the theory of incentives in copyrights [2]. From this viewpoint the idea-expression dichotomy can be seen as a solution that allows avoiding complexity of examination for qualification for copyright protection, in the presence of plethora of copyrightable objects from the beginning of time. Essentially the contraction between originality and idea-expression dichotomy can be associated with the contradiction between idea and expression, as originality supports the idea-wise creative focus, while the idea-expression dichotomy connotes the denial of protection to ideas and supporting of the distinct expression focus.

Divergence of originality, disregard to the labor and skill, and uniformity in expression focus. Widely replicated Feist case setting the US standard of originality require independent creation and 'modiculum of creativity' [3], while English law standard is prominent by 'labor and skills' test, and EU 'own intellectual creation standard' [4], inspired absolutist position of the notion of property in Civil law legal tradition [5], and based on the proprietorship dictated by normativism advocating individual autonomy in copyrights [6]. The difference in qualification criteria of the standards is being widely consolidated by the uniform approach on the idea-expression dichotomy. The meaning of originality as originating from author rather than absolute novelty is showing its clear dominance in Common law jurisdictions. Peterson J. in University of London Press Ltd v University Tutorial Press Ltd, acknowledges that the "The originality which is relates to the expression of the thought [7]. But the Act does not require that the expression must be in an original or novel form, but that the work must not be copied from another work - that it should originate from the author." According to Painer [8], "an author's own" means no more than that the work is originates from the 
author and is not copied [9]" Raise of the originated expression emphasis consequently lowered creativity threshold of originality. As noted by Mummery L.J. in Sawkins v Hyperion "A work may be completely rubbish and utterly worthless, but copyright protection may be available for it" [10]. Expression focus of originality can lead to its narrow interpretation limiting the protection to the ordinary technical effort of person claiming for authorship, which is linked with the contrasting interpretation of these concepts. While they are intervened and coexist as a 'form and substance' [11]. Labor and skills that was evolved as a distinctive feature of English Law, in contrast with the higher 'own intellectual creation' standard of Civil Law legal tradition. In Ladbroke $\mathrm{v}$ William Hill, Devlin LJ emphasized that "the requirement of originality means that the product must originate from the author in the sense that it is the result of a substantial degree of skill, industry or experience employed by him." Halsbury LJ in Walter v. Lane noted that "I should very much regret it if I were compelled to come to the conclusion that the state of the law permitted one man to make profit and to appropriate to himself the labor, skill, and capital of another" [12]. However positions distinguished by denial of labor and skills as viable criteria of originality are came into the scene. As noted by Oliver LJ in Interlego, with regard to the works done by "copying per se, however much skill or labor may be devoted to the process, cannot make an original work. A well-executed tracing is the result of much labor and skill but remains what it is, a tracing" [13]. Same position can be noticed in US contending that "It is unreasonable to say, as some courts have, that the copyright act bars one person from saving labor and time by using the works of another. On the contrary, avoidance of wasteful duplication of effort is one of the policies underlying the law of copyright" [14]. Expression focus of the copying is seemingly defeating the labor and skill, although any expression even lacking of creativity shall come up with the labor and skill. However it may be shortcoming to weight the intellectual works with the standards pertinent to the material objects, and creativity orientation remains as substantial criteria of originality. Although excluding the 'judgment' from the 'labor and skill' test may be shortcoming, as the exercising of judgment connotes making the choices as essential element of creativity.

The US approach is being somewhat distinct in framing the standard, known by statutory requirement to originality in Copyright Act 1976 and the Constitution, however without any clear definition or meaningful determination of originality from the courts [15]. Certain clarity on the standard although widely criticized was brought by the Feist case [16], where the use of the phone directory no matter to the presence of labor and skill haven't been found as infringing, evidencing disregard to the labor and skill in originality. Criticism to the Feist is in rejection of the fact-based labor-intensive works and diminishing the author-oriented personality notions and the "subjective" view on copyrights [17]. Feist's originality requirement of minimal level of creativity is being upheld without any prejudice to the idea-expression dichotomy that was originating much earlier in the jurisdiction. The U.S. notion of "idea-expression" dichotomy is deriving from Baker v. Selden [18], that made reference on protectable author's unique explanation of the systems of bookkeeping forms, while not preventing from the use of the actual systems of forms. In comparison of the Feist and Baker cases, some concordance of the standards of originality and idea-expression dichotomy can be noticed in analogy of Feist's exclusion of the fact-based work, and in Baker exclusion of the standard forms, hence disregarding the non-creative elements. However the outcome of the cases may be predefined by similar factbased issue that preclude the examination of the creativity in works.

\section{Shortcomings of copyrights in defining the originality}

Inconsistency of the Copyrights in framing the originality can be seen in lack of consideration of creativity in dominant theories of copyright [19]. "The acknowledged difficulties in drawing distinctions between ideas and expressions in copyright doctrine are rooted in the ways that copyright theory views creative processes" [20]. Absence of attention to the context and cultural gaze in assessment of originality and in copyrights having its merits, however encounter the nonsuitability of the legal framework in identification and assessment of that. Legally tailored standard of originality having difficulty to operate with creativity even at minimum level, which for that purpose is being replaced by the requirement of original expression. Although separating the new ideas from existing ones could be less challenging, than to separate ideas from expressions. Setting non-legal mechanisms of detecting the creativity isn't totally alien for the intellectual property, as for instance examination for objective similarity inherent to the trademarks.

Nowadays the reuse of ideas is widespread and forming the substantial basis the media industry and non-protection of ideas is allowing and to some extent even incentivizing that. The ideaexpression dichotomy herewith disregards the reality that the idea itself is the most merited substance of the work, as fulfilling the idea with the facts is merely the lower skill work. The idea-expression dichotomy that is equally applicable to preexisting and novel ideas, being rare and especially valuable nowadays, most assuredly after creation will be rendered for the sake of humanity and also sacrificed to the authors who expecting to give it a new expression. Herewith the reuse of ideas fostering position that the law protecting foxes better than the hedgehogs' [21]. The patents law which is considered to be the framework for the protection of ideas, even in its expansionist view, does not allow to protect ideas pertaining to the literary or artistic works, and have a clear focus on the implementation of idea rather than its communication envisaged by the type of IP as duty to disclose.

\section{Problems of distinguishing the idea and expression}

As the copyright protection is distanced from the protection ideas the focus in originality is made on the distinctive expressions. "The real task in a copyright infringement action, then, is to determine whether there has been copying of the expression of an idea rather than just the idea itself. The difficulty comes in attempting to distill the unprotected idea from the protected expression" [22]. Challenge is being associated with expressing the ideas in the same form as original expressions, as "...idea cannot exist apart from some expression" [11]. This however does not mean association of the expressions with the mere facts and rough information, as the source of original works. The facts are being tackled by parallel fact-expression dichotomy aimed at the exclusion of the protection of facts. In National Basketball Association v. Motorolla, Inc. emphasized on non-copyrightable nature of the facts, in example of N.B.A. game scores displayed by the Motorola handheld pager [23].

In the case of distinguishing the ideas from expressions, the question remains on the level of abstraction necessary to reach the essentials of idea, and not overly refine it to the general concepts. Conversely the question on uniform ratio of similarity necessary to differentiate the imitated expression from the original one. This leads to the contention that "Idea-Expression dichotomy is imprecise, though useful as analytic tool in separating infringing from noninfringing works" [24]. Definitely there are technologies and tools in place to tackle the task in the case of actual infringement. The 
abstraction-filtration test developed in Altai case adopts the abstractions test for separating the ideas from expression [25], for answering the questions of infringement of computer programs [20]. However the tools are not universally applicable and divergence in acceptable and infringing similarity is exists. Inseparability of the idea and expression is also a problem, that as suggested by Apple Computer, Inc. v. Formula International, Inc. can lead to the exclusion of the copyright ability of expression [26]. In pragmatic approach inviolability of the 'status quo' in non-protection of ideas urges to focus on the protectable and non-protectable expressions. "Drawing a distinction between the terms "idea" and "expression" cannot serve as a fundamental determinant for deciding what is protectable under copyright law. Rather, the sole distinction to be made is between those expressions which are protectable and those which are unprotectable" [11]. Courts do not have to abstract ideas from expressions but only to separate unprotectible from protectible expressions in the work". However creativity orientation of originality, even at minimum level, challenging at the least the idea part of the idea-expression dichotomy.

\section{Quality focus of the substantial copying}

Substantial copying as one of the essential elements of the copyright violation, which preclude unnecessary legal response to the minor or incidental actions, which allegedly infringe the rights of the copyright owner. In Ladbroke v William Hill regarding the compilation of the football coupons made of copied images and graphs, the partial copying was found as being subject to the substantiality requirement [27]. In connection with it, insubstantiality of the copied elements in Sillitoe v. McGraw-Hill Book, led to the absence of infringement [28]. However in qualification to the substantial copying in Ravenscroft $\mathrm{v}$ Herbert, analysis of the volume of taken part focused on its quality rather than quantity aspect [29]. There are reasons to believe that quality focus of substantial copying is more pertinent to the idea rather than expression, as the quantity is more on the side of expression of the work. The attention on the copying of central episode of the story considered to be the criterion of the substantiality of violation, and the central episode of the story is normally comprise the core idea of the work. This upholds the presumption on primacy of originality over the idea-expression dichotomy while in some extent prejudicing the general non-idea focus of originality. This means that de-facto ideas are still being subject of scrutiny in analysis of the copyright violation, which is consonant with ongoing attempts to revise originality towards the greater creativity inclination rather that non-similarity focus. This can be associated with concentration on the primary matter scrutinizing the essentials of originality, which is the creativity as sound determinant of originality in copyrights.

Another question appears with regard to these concepts, is their potential operation in different dimensions (one in technical and another in conceptual) without conflicting each-other. However pertaining of the both concepts to the same grounds, and the ideas being the result of creativity, leaves little assurance on parallel operation of the concepts. Focus on the protection on the products of the creativity rather than creativity itself, having immanent practical application and found its embodiment in the fixation requirement of the copyright. Since the attainment of the threshold of idea-expression dichotomy is more likely than the minimum level of creativity of originality (databases or other fact based works), it can support the presumption on the lower limit and the higher limits of these two standards. However it is difficult to argue that originality is setting the floor and idea-expression dichotomy is the ceiling in a sense of minimum level of creativity is the floor and expression as a sealing in arguable notion of the expression of different levels of creativity. When the works are necessarily expressed in a way not similar to others, but may still be lacking of creativity, similarly to the Feist case, here's the originality requirement can still be found as defeating the ideaexpression dichotomy. Herewith some sort of subtle primacy of originality over the idea-expression dichotomy can be traced. This is also can raise the question on consistency of the idea-expression dichotomy, rather than originality requirement.

From the viewpoint of Idea-Expression dichotomy, another product based on the same idea would not be infringing, as soon as it's differently expressed. This is being guaranteed by the lower threshold of creativity, which rising the question of feasibility of the protection at all. Quite a robust copyrights protection given for the works possessing minimum level of creativity can be considered as a mismatch [30]. The notion of minimal level of creativity is not incentivizing the creation of works with higher degree of originality [31]. Normally it is the originality that shall be a mechanism that restricts protection the works having low level of creativity. However raising the threshold of originality can become an encroachment to the idea sphere and ultimately violate an idea-expression dichotomy, which tells about mutual contradictory nature of these concepts. Lowering the level of originality is the necessary measure taken towards the mitigation of contradiction of the concepts, letting the works utilizing the same idea to pass the thresholds of originality. This mitigation allowed operation of the concepts as complementary rather than contradictory, no matter to the obvious lack of congruence among them.

\section{Originality and the personality theory}

As originality refers to the originator hence the author, some interlink of expression based originality with personality can be traced. In Burrow-Giles Lithographic Co. v. Sarony [32] "if the author of a work is defined as its originator, it follows that a work must have the characteristic of being original, or at least being originated, to be eligible for copyright protection" [33]. Based on the Bleistein, "The copy is the personal reaction of an individual upon nature. Personality always contains something unique. It expresses its singularity even in handwriting, and a very modest grade of art has in it something irreducible, which is one man's alone" [34]. "Following the Bleistein, later judicial statements described originality in terms of individual effort without regard to any degree of novelty or aesthetic merit" [35]. Persistence of the novel analogies of the theory is still vivid in the French test focusing on the personality where the creative choices were determinant [36]. In the Painter case the court commenting the meaning of the 'own', stating that "intellectual creation is an author's own if it reflects the author's personality" [8].

Construction of originality as synonymous to the personal expression supporting the subjective standard of originality and seems to be consonant with the permissive operation with ideas. "Originality is created through individualized interpretation and creative thought. When an author is inspired by another author's work, it is safe for the author to borrow from these ideas and build upon them as long as his or her personality is reflected in the interpretive work". Obviously the personality is the concept out of which the originality in its current shape is having its inspiration. However strong property right claims distancing the personality from the creative essence of originality. Most likely protection of everything that was expressed hasn't been envisaged by the intellectual property law, exemplified in in Feist by rejection of the fact-based works lacking of creativity [3]. 
Looking at the other end of this modality, exorbitant focus on creativity in originality beyond the 'modiculum of creativity', can lead to the 'protection of the author's work subject to the level of creativity' [31]. The worst case scenario can be the ultimare monopolization of ideas which harms the freedom of ideas and open culture. However protection to the expression having current dominance can be considered as another end of this problem, which is arguably overly inclination towards the ordinary non-similarity of expression and lack of due regard to the creativity. "Quite a robust copyrights protection given for the works possessing minimum level of creativity can be considered as a mismatch" [30]. Some middle course or balanced approach with this regard can be more plausible. According to McLachlin C.J. in CCH Canadian Ltd v Law Society of Upper Canada, these conflicting approaches are representing the two extremes and correct position is between of these extremes" [37]. Similarly protection of expressions and the protection of ideas can be considered a 'extremes and the balanced position can be the middle course, in protection of the 'judgment' from labor and skill, movement of originality to higher degree of creativity or reducing the categorical line of idea-expression dichotomy towards the ideas.

\section{Conclusions}

The conflict of originality standard and idea-expression dichotomy is evidencing on existing inconsistencies in framing the limits the protectable domain. Obviously the rationale of the current position of law reasoned by the attempt to protect the most from the least. Current state of affairs with low standard of originality requires to be originated from the author and protection of expressions, is not incentivizing the creativity. The difficulties in delineating the ideas and expression, leaving the space for maneuvers for the parties of copyright disputes and contributing to the continuity of the dispute of original works and permissible replications. Contemporary unconformity of originality with idea-expression dichotomy necessitates to reconsider the standards moving it from extremes towards the balanced approach on recognition of the higher creativity in originality, or mitigation of categorical approach of idea-expression dichotomy, and recognition of 'judgment' criteria from the 'labor and skill' standard, that can consecutively lead to the synchronization of the standards. Legal practice over the copyright infringements and quality based substantial copying is evidencing on factual attention to creativity and the ideas in copyright protection. Also lower threshold of the attaining the expression than creativity to some extent can tell about subtle primacy of originality over the idea-expression dichotomy and possible interoperability of the concepts. This can be even more persuasive in the case of rendering higher attention to the creativity in originality that leads to the relaxation of the idea part of the idea-expression dichotomy. This is consonant with the attempts to reshape the originality toward the greater creativity focus, hence more essential aspect of the subject matter than non-similarity or personal expression. The obvious shortcomings of the copyright in establishing the sound criteria qualifying creativity is reasoned by non-legally palpable state of the phenomenon of creativity per se.

\section{References}

1. WIPO Database of Intellectual Property (1886) Berne Convention for the Protection of Literary and Artistic Works.

2. Balganesh S (2009) Foreseeability and Copyright Incentives. Harvard Law Review 122: 1569-1633.
3. U.S. Supreme Court (1991) Feist Publications inc. v. Rural Telephone Service Co. 499 U.S. 340.

4. Directive 2001/29/EC of the European Parliament and of the Council of 22 May 2001 on the harmonisation of certain aspects of copyright and related rights in the information society.

5. Simon N (2011) The development of copyright and moral rights in the European legal systems. European Intellectual Property Review 33: 677-689.

6. Risser R (2010) Creative Determinism and the Claim to Intellectual Property. The Monist 93: 353-367.

7. Peterson J (1916) University Press v University Tutorial Press. University of Cambridge.

8. Painer [2012] E.C.D.R. 6 at [88].

9. Liu D (2014) Of Originality: Originality in English copyright law: past and present, E.I.P.R. 36: 376-389.

10. Mance M, Jacob LJJ (2005) Hyperion Records Ltd v Sawkins: CA 191 W.L.R. 3281.

11. Jones RH (1990) The Myth of the Idea/Expression Dichotomy in Copyright Law. Pace Law Review 10: 551-606.

12. University of Cambridge (1900) Walter v. Lane A.C. 539 at 545.

13. Interlego AG v Tyco Industries Inc [1989] A.C. 217 PC (Hong Kong).

14. Gorman RA (1963) Harvard Law Review 76: 1569-1605 at 1604.

15. VerSteeg R (1993) Rethinking Originality. Wm. \& Mary L. 34: 801-883.

16. U.S. Supreme Court (1991) Feist Publication v Rural Telephone Service Co Inc, 499 U.S. 340.

17. Ginsburg JC (1992) No "Sweat"? Copyright and Other Protection of Works of Information After Feist v. Rural Telephone. Columbia Law Review 92: 338-388.

18. U.S. Supreme Court (1873) Baker v. Selden, 101 US 99.

19. Cohen JE (2007) Creativity and Culture in Copyright Theory, 40 UC DAVIS L. Rev. 1151.

20. Arewa OB, The Freedom to Copy: Copyright, Creation, and Context, UC Davis 41. At 491

21. Daniel Gervais (2013) The Derivative Right, or Why Copyright Law Protects Foxes Better than Hedgehogs. Vand. J. Ent. \& Tech. L. 15: 785

22. Sid \& Marty Krofft Television Productions, Inc. v. McDonald's Corp. 562 F.2d 1157 (9th Cir. 1977).

23. National Basketball Assoc. v. Motorola, Inc., 105 F.3d 841, 843 (2d Cir. 1997).

24. Warner Bros. v. Am. Broad. Co., 720 F.2d 231 (2nd Cir. 1983).

25. Computer Associates Int'l, Inc. v. Altai, Inc. 982 F.2d 693 (2d Cir. 1992).

26. Apple Computer, Inc. v. Formula International, Inc., 725 F.2d 521, 523 (9th Cir. 1984).

27. Ladbroke v William Hill [1964] 1 All ER 465.

28. Sillitoe v McGraw-Hill Book Co [1983] FSR 545.

29. Ravenscroft v Herbert [1980] RPC 193.

30. Samson Vermont (2012) The Sine Qua Non of Copyright is Uniqueness, Not Originality. Tex. Intell. Prop. L.J. 327.

31. Gideon Parchomovsky, Alex Stein (2009) Originality. Virgina Law Review 95: 1505-1550.

32. Burrow-Giles Lithographic Co. v. Sarony, 111 US 53 (1884).

33. Abrams HB (1332) Originality and Creativity in Copyright Law. Law and Contemporary Problems 55: 1-44.

34. Bleistein v. Donaldson Lithographing Co., 188 U.S. 239 (1903).

35. Judge EF, Gervais D (2009) Of Silos and Constellations: Comparing Notions of Originality in Copyright Law. Cardozo Arts \& Entertainment Law Journal 27.

36. Lauren Rieders (2007) Borrowing and Originality in Modern Authorship. Lehigh Review 15: 10-19.

37. CCH Canadian Ltd v Law Society of Upper Canada [2004] 1 SCR 339. 